1 Universidade Federal de São Paulo (Unifesp) - São Paulo (SP), Brasil.

lumenafurtado@gmail.com

\section{Caminhos metodológicos de pesquisa participativa que analisa vivências na pandemia de Covid-19 em populações vulneráveis}

\author{
Participative research methodology: paths to analyse the experiences \\ of vulnerable populations during the Covid-19 pandemic
}

Lumena Almeida Castro Furtado', Claudia Fegadolli1, Arthur Chioro', Anderson Kazuo Nakano, Cristiane Gonçalves da Silva', Liana de Paula', Luciana Rosa de Souza', Mariana Arantes Nasser ${ }^{\mathbf{1}}$

DOI: 10.1590/0103-11042020E421

\begin{abstract}
RESUMO O objetivo geral do artigo foi compartilhar a investigação em curso que se propõe a analisar as vivências, os processos e os impactos sistêmicos da pandemia de Covid-19 e das medidas e ações realizadas para a sua prevenção, contenção e enfrentamento. $O$ estudo considera as desigualdades nas vivências da pandemia em populações de diferentes territórios vulneráveis. São 14 territórios da Região Metropolitana de São Paulo e da Baixada Santista. O delineamento da pesquisa busca qualificar o olhar para a vivência da pandemia em sua complexidade, via produção interdisciplinar do conhecimento, realizada com as populações estudadas. O coletivo de pesquisadores é formado por moradores dos territórios, estudantes e pesquisadores ligados à universidade. Unifica este coletivo o compromisso de produzir conhecimentos científicos socialmente referenciados. O desenvolvimento da pesquisa, em cada território, produzida em conjunto com pesquisadores sociais e organizações coletivas, tem permitido uma reflexão crítica e visibilizado a centralidade das redes construídas pelos atores locais. Esse percurso permite considerar o modo de produzir vida em territórios marcados pela desigualdade e reconhecer seus desafios. Caminhar nesse complexo processo atravessado pela pandemia é o desafio e a riqueza desse estudo.
\end{abstract}

PALAVRAS-CHAVE Infecções por coronavírus. Iniquidade social. Vulnerabilidade social. Território sociocultural. Pesquisa participativa baseada na comunidade.

ABSTRACT This paper presents an ongoing investigation that analyzes life experiences, processes and systemic impacts of the Covid-19 pandemic and examines the measures and actions to prevent, contain and respond to it. The study focuses on the inequalities of life experiences of the pandemic in populations that live in fourteen vulnerable territories of the Metropolitan Area of São Paulo and the city of Santos (Brazil). The group of researchers is composed of people who live in those territories and students and professors of the Federal University of São Paulo. The research design focuses on comprehending the experience of the pandemic in its complexity, through an interdisciplinary production of scientific knowledge that is socially referenced and committed to the participation of the populations studied. The field research in each territory, which counts with the participation of local organizations, is producing a critical reflection on the experience of the pandemic and giving visibility to the centrality of social networks weaved by local actors. This path allows us to understand the ways of producing life in territories stressed by inequality and to recognize their challenges. To go through this complex process crossed by the pandemic is the challenge and the richness of this study.

KEYWORDS Coronavirus infections. Social inequity. Social vulnerability. Sociocultural territory. Communitybased participatory research. 


\section{Introdução}

O desenvolvimento da pandemia de Covid-19 colocou para todos os países grandes desafios no enfrentamento de um fenômeno que ainda se apresenta com muitas incertezas, mas que indubitavelmente produz um impacto importante para toda a população.

A chegada da pandemia no Hemisfério Sul agrega a esse desafio um outro problema ainda mais desafiador: o impacto diferenciado sobre as populações vulneráveis. No Brasil, país de imensa extensão territorial, superpopuloso e marcado por uma considerável heterogeneidade regional, a enorme desigualdade social tem escancarado aquilo que já se evidenciava antes da pandemia: nem todas as vidas têm o mesmo valor.

Na perspectiva deste estudo, é fundamental aprofundar o olhar sobre as populações vulneráveis nos diferentes territórios, identificando como vivem e como são afetadas pela pandemia, além de conhecer o impacto e os efeitos de políticas públicas e das organizações e movimentos sociais nessa vivência.

Uma pesquisa da Fundação Getulio Vargas ${ }^{1}$ indica aumento da pobreza e da desigualdade no Brasil nos últimos anos. Segundo o estudo, em 2018, havia 23,3 milhões de pessoas vivendo abaixo da linha de pobreza, com rendimentos abaixo de R $\$ 232$ por mês; cerca de $11,2 \%$ da população. A miséria subiu 33\% de 2015 a 2018. Foram 6,3 milhões de novos pobres - mais do que a população do Paraguai - adicionados ao estoque de pobreza.

Neste país desigual, segundo a análise de Martins ${ }^{2}$ :

Em meio a tantas incertezas, uma certeza: enquanto persistirem estes padrões de desigualdade, são os trabalhadores, suas famílias e comunidades que vão sucumbir à COVID-19. Estão sendo empurrados a uma escolha perversa e mentirosa entre a atividade econômica, assegurando o alimento, ou o isolamento social, garantindo a sobrevivência².
Dessa forma, um país já profundamente desigual - que vinha ampliando essa desigualdade nos últimos anos -, com a chegada da pandemia, passou a viver um agravamento dessa situação. Santos ${ }^{3}$ analisa a alta correlação entre as condições sociais, classe e território e seu impacto direto no processo de adoecimento e morte pela Covid-19, sinalizando a relação direta entre a pandemia e a ampliação da desigualdade.

A subnotificação de dados de morbimortalidade por Covid-19, resultante da baixa testagem, tanto para investigação diagnóstica como para análise da soroprevalência e orientação das medidas sanitárias, em conjunto com a divulgação de informações contraditórias e desencontradas, às vezes falsas, criam uma disputa de discursos que podem levar a uma grande confusão e insegurança na população sobre que medidas tomar. Esse estado de coisas dificulta a construção de visões fidedignas sobre o comportamento da pandemia que, por conseguinte, limitam ou distorcem sobremaneira a implantação de ações de enfrentamento necessárias e fundamentadas em diretrizes científicas sólidas.

Mesmo com a enorme subnotificação, tanto de infectados como de óbitos, ultrapassar a marca de 100 mil mortes ${ }^{4}$ em 8 de agosto de 2020 evidencia o descontrole e a falta de gestão central por parte do governo federal e, em particular, pelo Ministério da Saúde. Ressalta-se que esse número é significativamente subestimado, pois os testes são restritos aos casos muito graves. O aumento das mortes por Síndromes Respiratórias Agudas Graves (SRAG) inespecíficas evidencia a imprecisão dos dados de mortalidade.

A evolução da mortalidade, em uma pandemia que começou nas classes altas e média, quando vivida pelas populações vulneráveis, escancara a enorme desigualdade social brasileira. O gráfico 1 e a figura 1 mostram a forte relação entre condição econômica com a mortalidade pela pandemia. 
Gráfico 1. Distribuição de mortes por Covid-19 na Grande São Paulo, segundo renda familiar, 2020

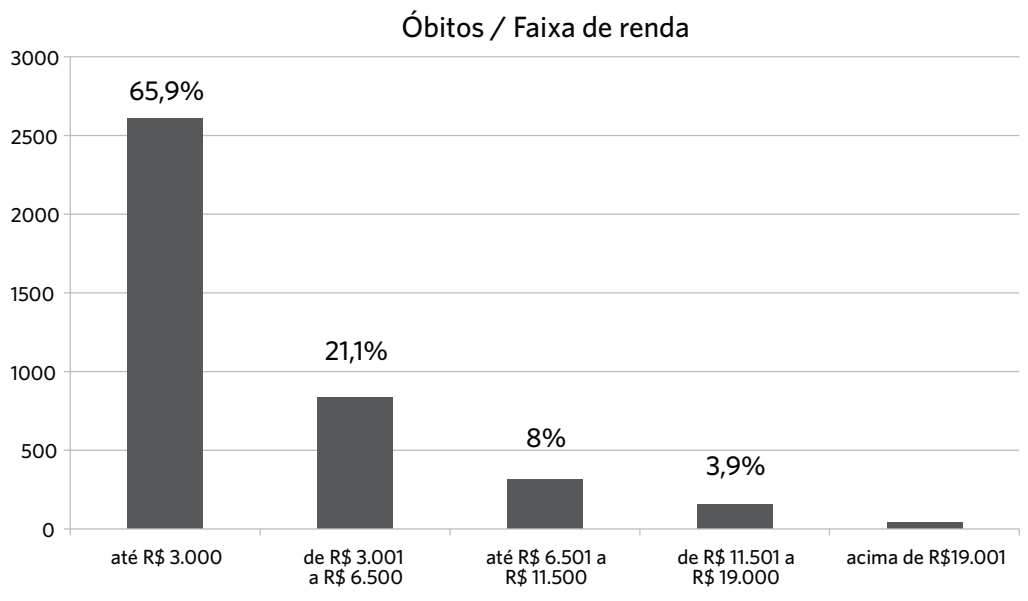

TOTAL: R\$3.959

Fonte: Medida SP5, a partir do Datasus e do Censo 2010, adaptacão dos autores.

Figura 1. Distribuição de mortes por Covid-19 na Grande São Paulo, segundo renda familiar e idade, 2020
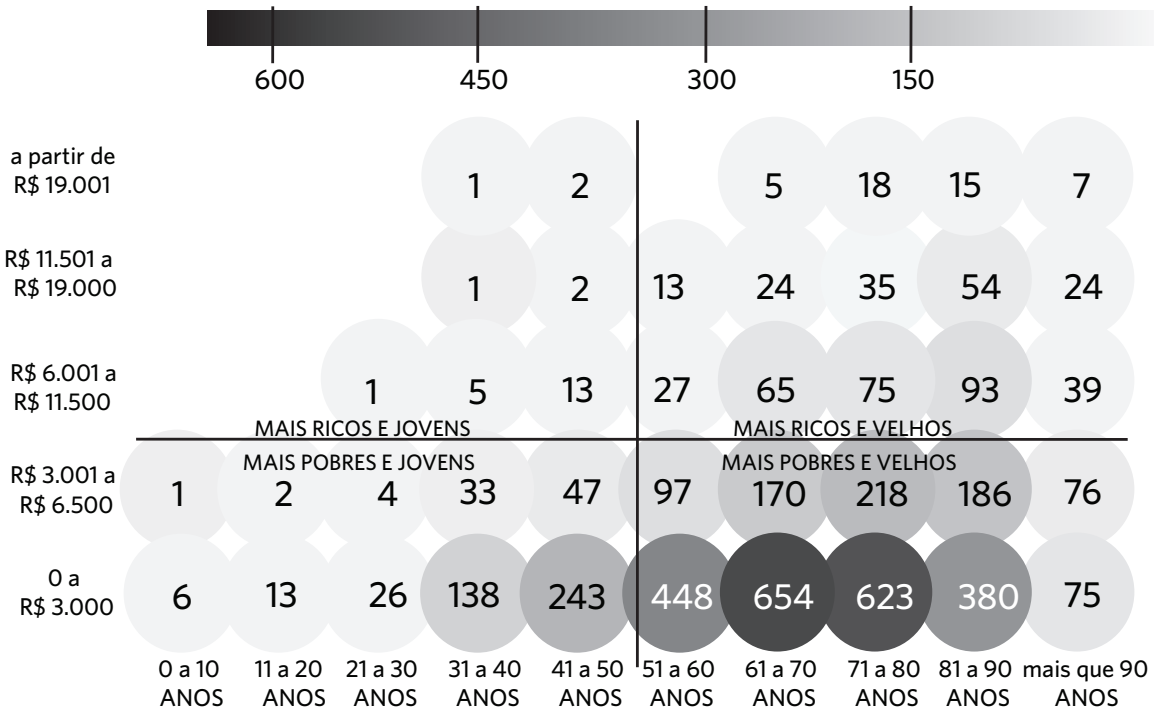

Fonte: Medida SP5, a partir do Datasus e do Censo 2010, adaptação dos autores.

Ainda que esses números não deixem dúvidas sobre o impacto da desigualdade na mortalidade pela pandemia, ganhou força em nosso país um debate, transformado em polêmica nacional, relacionado com um falso dilema: salvar a economia ou salvar as vidas das pessoas. Nos diferentes setores do Estado brasileiro, posições quanto a esse debate têm 
sido conflitantes e explicitam diferenças importantes em relação aos valores e aos compromissos políticos com as necessidades sociais e existenciais diante dos impactos provocados pela pandemia de Covid-19.

Mbembe $^{6}$ ressalta que a priorização da economia em detrimento das vidas humanas evoca a necropolítica, a qual "[...] é a lógica do sacrifício que sempre esteve no coração do neoliberalismo". Essa lógica cria a possibilidade de pedir para que parte da população assuma situações de risco a fim de manter o funcionamento e a continuidade das atividades econômicas, mesmo que isso custe incomensuráveis vidas humanas. Uma postura perversa de individualizar a responsabilidade pela adesão às medidas protetivas, eximindo o Estado de seu papel provedor de direitos, o que agrava a enorme desigualdade já existente e aquela proporcionada pela vivência da pandemia por populações vulneráveis.

A individualização da responsabilidade em adotar medidas de proteção ante a pandemia é uma face perversa da necropolítica referida por Mbembe $^{6}$. Como exigir que populações em situação de rua, presidiários e moradores de favelas e cortiços, sem apoio do Estado, possam garantir as medidas de minimização de risco necessárias, sem acesso à água, sem casa ou vivendo em habitações que exigem que muitas pessoas dividam o mesmo cômodo ou ambiente?

A partir dessa inequívoca situação de desigualdade, o objetivo geral do artigo é o de compartilhar a investigação em curso, que se propõe a analisar as vivências, os processos e os impactos sistêmicos da pandemia de Covid-19, inclusive das medidas e ações realizadas para a sua prevenção, contenção e enfrentamento. O manuscrito visa aportar elementos para o aprofundamento das reflexões sobre o papel e as contribuições das pesquisas participativas nos estudos sobre a vivência da pandemia em territórios com maior vulnerabilidade. Com o crescimento da pandemia e dos óbitos nessas populações, ganha centralidade a reflexão sobre métodos de produção do conhecimento relacionados com essas populações. Trata-se de um estudo que considera as desigualdades das vulnerabilidades nas vivências, os processos e os impactos sistêmicos da Covid-19, bem como as formas de operacionalização de redes de apoio, de ajuda mútua e de solidariedade que atuam nos territórios selecionados para o estudo. Unifica o coletivo de pesquisadores responsáveis pelo estudo o compromisso de produzir conhecimentos científicos socialmente referenciados ${ }^{7}$.

Consideramos fundamental que cientistas que se dedicam a diferentes áreas do conhecimento desenvolvam seus trabalhos de forma implicada com a produção de conhecimentos mais consistentes e precisos a respeito da pandemia ${ }^{8}$. Esta pesquisa agrega cientistas e pesquisadores de diferentes áreas, articulados em um esforço comum de ampliar a compreensão sobre as vivências, os processos e os impactos sistêmicos da pandemia em diferentes territórios, localizados em municípios da Região Metropolitana de São Paulo (Diadema, Guarulhos, Osasco e São Paulo) e em SantosSP, cidades em que a Universidade Federal de São Paulo (Unifesp) mantém campi ${ }^{9}$.

Em um momento em que as universidades públicas se encontram sob ataque e no qual o conhecimento científico é deslegitimado por discursos retrógrados, negacionistas, revisionistas e obscurantistas, explode a pandemia de Covid-19, que, entre diversos efeitos, provoca forte tensão entre as explicações racionais, formuladas segundo os métodos lógicos e científicos e as opiniões infundadas disseminadas por representantes de algumas esferas de governo e pelos canais de comunicação atuais.

Considerando esse contexto e provocados por um edital elaborado no âmbito do convênio entre a Unifesp e a Fundação Tide Setúbal, desenvolvem a investigação em curso aqui apresentada 108 pesquisadores, incluindo docentes de diferentes formações e alunos de seis campi (São Paulo, Zona Leste, Osasco, Diadema, Guarulhos e Baixada Santista), assim como bolsistas dos 16 territórios selecionados para a realização da pesquisa de campo. 
Importantes desafios ajudam a refletir sobre o papel das universidades na sociedade. Esta pesquisa tem dialogado diretamente com dois deles: o primeiro é a necessidade de ampliar a interdisciplinaridade no processo de formação e atuação da universidade; o segundo é a reflexão sobre a inserção e a porosidade da produção universitária em relação aos problemas sociais que se colocam em diversos territórios ${ }^{10}$. O desenvolvimento da pesquisa, a partir de seus objetivos, dialoga com tais desafios e pode se constituir uma experiência de enfrentamento da histórica separação e disputa entre os saberes, com o aprofundamento de uma perspectiva interdisciplinar e da importância de uma pesquisa participativa construída com os movimentos sociais em cada território.

A pesquisa foi aprovada pelo Comitê de Ética em Pesquisa da Unifesp pelo parecer de número 4.091.794.

\section{A produção da investigação}

Como se trata de um ensaio que se propõe a analisar uma pesquisa ainda em curso, um propósito central deste artigo é problematizar o caminho metodológico construído, suas potencialidades e desafios.

Esta pesquisa foi estruturada pelo delineamento de estudos de casos múltiplos e pesquisa participante com a confluência de diversos campos disciplinares ${ }^{11-13}$.

Cada um dos 16 territórios constitutivos da pesquisa pode ser entendido como um caso (objeto empírico) a ser sistematizado e está sendo analisado como múltiplos casos, segundo abordagens adequadas às condições nas quais se tem pouco controle sobre os eventos inseridos em contextos da vida real'1. Cada caso deve contribuir para um conhecimento em profundidade. Os diversos casos, tomados em conjunto, podem contribuir para a generalização do conhecimento, tendo em vista a pandemia em áreas metropolitanas e as interfaces com as desigualdades nos territórios com vulnerabilidades.
O estudo foi estruturado a partir de territórios relacionados com seis campi da Unifesp:

- Campus São Paulo: 5 territórios, localizados na Comunidade de Heliópolis; na Vila Mariana - que pode ser tomada como 2 territórios, sendo um composto por população predominante e de classe média e outro por 15 pequenas comunidades (Mário Cardim, Mangueira, Souza Ramos 1 e 2, Onze de Junho 1 e 2, Fazendinha, Cercadinho, Vila Z, Santo Irineu, Helen Keller, Loefgreen Singapura, Madre Cabrini, Caixa d'Água e União), que se articulam e totalizam aproximadamente 10 mil pessoas, segundo liderança comunitária) - ; no bairro da Luz - área pejorativamente conhecida como 'Cracolândia' (terminologia utilizada para desqualificar o território e justificar ações higienistas, policialescas e autoritárias) e, por sugestão dos bolsistas sociais desse território, ele será nomeado como Fluxo; e na Vila São José.

- Campus Zona Leste: 2 territórios localizados um no Jardim Helian e outro composto por Vila Miguel Inácio Curi e pela Vila da Paz;

- Campus Diadema: 1 território localizado no bairro Eldorado;

- Campus Osasco: 4 territórios localizados nos bairros Quitaúna, Portal D’Oeste 1, Bandeiras e Morro do Socó;

- Campus Baixada Santista: 2 territórios localizados nos bairros Saboó e Alemoa;

- Campus Guarulhos: 2 territórios localizados no conjunto habitacional Residencial Esplanada e na comunidade negra atendida pelo Núcleo Mabel Assis, da Rede Uneafro.

Ressalta-se, aqui, um primeiro desafio, que é o de pesquisar 16 territórios distribuídos em 6 campi e 5 municípios, considerando suas diversidades constitutivas e as situações de vulnerabilidade e desigualdade que também se apresentam com muitas semelhanças.

Um importante dispositivo de enfrentamento desse desafio foi assumir que a pesquisa participativa se realiza com a população moradora de cada território ${ }^{\mathbf{1 4}}$.

Assim, os coordenadores em cada campus aprofundaram um processo de articulação com os movimentos sociais, lideranças 
comunitárias e moradores que vivem e atuam em tais territórios. Desse processo, resultou um grupo de pesquisadores que envolve um total de 60 bolsistas, sendo que 24 são pesquisadores comunitários, escolhidos a partir dos territórios, 12 bolsistas de ensino médio que também são pesquisadores comunitários, e 18 bolsistas estudantes de diferentes cursos de graduação da Unifesp. Cada campus conta com um bolsista coordenador da pesquisa de campo. Somam-se a esse coletivo 48 pesquisadores com vínculo com a universidade, compondo, dessa forma, um coletivo de 108 pesquisadores, todos com responsabilidades na condução da pesquisa.

A participação ativa dos envolvidos, além de ser princípio ético deste estudo, está em consonância com o campo político que exige o estabelecimento de diálogos mais equitativos para a construção de conhecimentos e das soluções para os desafios impostos pela pandemia, em abordagens baseadas nos direitos humanos ${ }^{15}$. Trata-se de uma pesquisa que conta com a participação calcada em fundamentos freirianos expressos em todo o seu processo, norteados pela perspectiva comunitária e pela produção de relações mais horizontalizadas ${ }^{13}$. Foi assumida a importância de 'pesquisar com' ao invés de 'pesquisar sobre', de modo a construir um olhar compartilhado em relação ao que está sendo investigado ${ }^{16}$.

A fim de garantir a variabilidade dos dados requerida para a construção de conhecimentos em profundidade de cada caso, definiram-se as seguintes técnicas de pesquisa: a) análise das desigualdades nas vulnerabilidades à Covid-19 por meio de indicadores sociodemográficos e de condições de vida e saúde, baseados em dados secundários; b) análise documental de entrevistas, reportagens e pesquisas científicas veiculadas em meios de comunicação e em bases de dados científicas; c) diário de campo; d) questionários estruturados e entrevistas semiestruturadas sobre perfis sociodemográficos, condições de moradia, efeitos sistêmicos, percepções e vivências das pessoas relativas à pandemia de Covid-19; e) rodas de conversa sobre a pandemia de Covid19 no que diz respeito às percepções sobre o acesso a informações, rotinas, adoção ou não de medidas de prevenção, impactos nas condições de vida, situações de violência, experiências de adoecimento e de morte de pessoas próximas, influências para a renda e apoios recebidos ou fornecidos, dentre outros aspectos; f) usuários-guia para a construção de narrativas sobre os mapas de cuidado e a vivência em relação à pandemia de Covid-19.

As técnicas de pesquisa mencionadas anteriormente servem à elaboração de análises sobre quatro questões-problemas:

- o acesso à informação e a adesão às estratégias e táticas de prevenção e combate à disseminação da Covid-19;

- as restrições às condições de mobilidade das pessoas, o isolamento domiciliar, as condições urbanas-habitacionais dos moradores, a violência doméstica baseada no gênero e sexual, o sofrimento mental, o fechamento de escolas e a descontinuidade na oferta pública e privada de serviços essenciais;

- a perda de renda, o aumento da pobreza e a insegurança alimentar e nutricional;

- a produção da saúde.

Neste ponto, um segundo desafio metodológico se coloca: como articular 108 pesquisadores, de diferentes formações acadêmicas, portadores de distintos referenciais teóricos, com experiências e interseções com o objeto da pesquisa bastante distintos?

Um dispositivo central tem sido a construção de diferentes procedimentos para a formação do coletivo de pesquisadores, a partir de pressupostos e referências centrais na pesquisa que se organizam a partir de oficinas, rodas de conversa temáticas e reuniões em cada território e campus. Esse desafio se amplia pelo momento de vivência da própria pandemia, a qual exige um isolamento social, que é vivido de distintas formas pelo grupo de pesquisadores.

A construção coletiva de cada instrumento de pesquisa é outro dispositivo de qualificação desse processo metodológico, que aposta na 
importância da interdisciplinaridade na produção do conhecimento e na necessidade de construir os instrumentos de investigação com os pesquisadores, em forte conexão com as necessidades e características de cada território.

Esse percurso metodológico foi iniciado pela construção do questionário estruturado que abriu a entrada em campo. Da mesma maneira, os diferentes referenciais e experiências se colocam como um desafio que tem estimulado o coletivo de pesquisadores na construção de novas possibilidades de articulação de todos os envolvidos.

O questionário foi construído em quatro fases distintas, cada uma composta por diversas etapas. Estas foram: a definição de conteúdo e elaboração de itens, validação de conteúdo por comitê de especialistas e estudo-piloto, com ajustes no instrumento para obtenção da versão final. Essa tarefa, que já não é simples quando os pesquisadores fazem parte de grupos mais homogêneos de pesquisa, torna-se mais complexa pela diversidade de formação dos pesquisadores e, portanto, pela ênfase diferente dada a cada variável e pela necessidade de produzir um instrumento não muito extenso. Este momento, mais do que uma junção de várias áreas do conhecimento, representa uma oportunidade de aprofundamento da potência da construção interdisciplinar, a qual enriquece a abordagem plural do fenômeno estudado. O questionário para o território do Fluxo foi construído com os pesquisadores daquele território, adaptando tamanho e linguagem.

As próximas etapas preveem a aplicação de instrumentos de abordagem qualitativa. A observação participante, um importante instrumento filiado à pesquisa qualitativa ${ }^{17,18}$, demarca que a pesquisa terá como princípio a participação de todos envolvidos. O diário de campo é o registro da observação participante. Sua instituição se deu desde o início da chegada dos bolsistas, a partir dos primeiros treinamentos, possibilitando a coleta de informações e de percepções sobre os territórios e acerca do próprio processo de trabalho. $\mathrm{O}$ diário de campo vem contribuindo para todo o balizamento da pesquisa, incluindo a continuidade do percurso metodológico, com o registro singular de cada pesquisador.

A metodologia do usuário-guia, a ser identificado durante a realização dos demais procedimentos nos territórios, permitirá que os pesquisadores sejam guiados por um dos moradores do território, que ele seja o guia. Assim, a partir das perguntas iniciais da pesquisa, será possível aprofundar e construir outras que contribuirão para a definição do caminho a ser percorrido.

Está sendo também preparado o estudo dos dados secundários, com a perspectiva de contribuir para a caracterização socioterritorial dos locais em que os estudo se desenvolve. A construção de indicadores a partir de dados secundários exige, como primeiro passo, uma análise detalhada das características dos bancos de dados que podem vir a ser utilizados. É importante examinar os instrumentos de coleta de dados, os dicionários das variáveis utilizadas, as unidades de agregação dos dados ou microdados, os anos de coleta dos dados, entre outros aspectos, para compreender as possibilidades e limites destes. O banco de microdados da amostra do Censo Demográfico IBGE de 2010 é a única base de abrangência nacional que fornece dados a respeito das condições domiciliares e das características sociodemográficas dos moradores desagregadas em unidades submunicipais, o que é muito relevante no desenho da pesquisa.

Nesse sentido, estão em análise, além dos microdados, a pesquisa origem-destino do metrô de 2017; as bases identificadas e desidentificadas do CadÚnico e os dados de cadastro individual e domiciliar levantados pelos Agentes Comunitários de Saúde. Um desafio é vencer obstáculos relacionados com as diferentes unidades administrativas em que os dados estão disponíveis.

Uma parte importante da pesquisa é o inquérito de soroprevalência seriado em amostragem populacional estratificada. Trata-se de um estudo inédito, realizado em duas fases 
de testagem, em julho e agosto de 2020, com intervalo de um mês entre estas, o que permitirá avaliar o comportamento da pandemia em populações vulneráveis domiciliadas e em situação de rua. A análise está em curso; e por meio de inquérito sorológico, espera-se: i) estimar a prevalência de anticorpos contra o SARS-CoV-2 nas populações vulneráveis, distribuída por sexo, faixa etária e condições de moradia; ii) determinar o aumento do número de pessoas infectadas ao longo de um intervalo de 30 dias; iii) avaliar o número de pessoas com infecção, assintomáticas ou oligossintomáticas; iv) avaliar o nível de conhecimento populacional sobre as medidas de isolamento e os riscos de transmissão; v) determinar a situação epidemiológica dessa infecção em populações vulneráveis, com o intuito de fornecer subsídios e recomendações para os gestores do Sistema Único de Saúde (SUS). Trata-se, sobretudo, de um importante dispositivo para o aprofundamento do objetivo central deste estudo, que é o de ampliar a visibilidade para a vivência e para os impactos da pandemia nessas populações.

\section{Investigação em contexto de desigualdade}

O processo de construção da pesquisa tem permitido a produção de um conhecimento a respeito do território que revela a integração pesquisador-campo de pesquisa. A constituição do núcleo de pesquisa inicial, com 108 pesquisadores, teve como repercussão imediata a ampliação da participação. Para permitir o desenvolvimento participativo da pesquisa, foram constituídos comitês de acompanhamento em cada território com os pesquisadores sociais que ali moram, lideranças sociais e pesquisadores ligados à universidade que têm participado ativamente das discussões, levantamentos de questões e planejamento dos rumos da pesquisa.

O modo de pesquisar, inserido na vivência cotidiana em cada espaço, possibilita visibilizar associações entre a pandemia e a vulnerabilidade, tanto em relação aos seus aspectos mais objetivos, como condições de moradia, quanto aos mais subjetivos. Os diários de campo dos pesquisadores têm amplificado a importância de olharmos essas relações. Um deles escreveu:

temos percebido, em nosso cotidiano [...], que o número de pessoas desempregadas é cada vez maior. Isso faz com que muitas famílias fiquem com medo de que, nos próximos meses, já não consigam pagar aluguel, por exemplo. Nosso movimento acredita que a crise se agravará ainda mais. Teremos um número maior de pessoas desempregadas passando fome, correndo de risco de não terem onde morar. (Diário de campo, Pesquisador 1).

Impacta diretamente nessa relação da desigualdade com a vivência da pandemia o desmonte de políticas sociais, particularmente na saúde. O desfinanciamento do SUS provocado pela Emenda Constitucional 95, que congelou por 20 anos os recursos para a saúde, já agrava o desfinanciamento histórico SUS e impacta a possibilidade de ampliação da rede e de sua capacidade de organizar o cuidado na pandemia ${ }^{19}$.

A desigualdade social foi sendo absorvida acriticamente ao longo do tempo no País, possibilitando certa naturalização das mais de 130 mil mortes ${ }^{4}$ pela pandemia, em setembro de 2020. Análises que partem dessa naturalização não consideram a relação entre a mortalidade pelo vírus e o agravamento das questões econômicas e de aumento da pobreza, que caminham juntas. Visibilizar a produção político-social dessa mortalidade e reconhecer as populações em vulnerabilidade como sujeitos de direitos é fundamental para avançarmos no enfrentamento da pandemia e na qualificação de políticas públicas.

Este estudo é fortemente referenciado aos territórios estudados. Território tomado não apenas como um espaço geográfico, mas também existencial20, com a construção de muitos sentidos, um território em produção 
permanente, contínua, em ato. Assim, o conhecimento produzido neste estudo terá sempre conexão com esta produção viva do território.

Vulnerabilidade aqui agrega as dimensões de trabalho, renda, condições de moradia, acesso à alimentação, acesso à informação, escolaridade, rede social, acesso à rede de saúde, assim como as vivências relacionadas com raça/cor, gênero, identidade sexual e idade, com um olhar diferenciado para o agravamento da situação de desigualdade e para a vivência de violências, no contexto da pandemia para algumas populações específicas.

$\mathrm{O}$ desenho da pesquisa permite a participação dos sujeitos envolvidos, o que vai sendo visibilizado pelo desenrolar participativo e interdisciplinar do estudo, a partir do que emerge do campo. A análise busca a compreensão dos impactos da pandemia e das pistas para qualificar o seu enfrentamento pelas comunidades e a produção de sugestões para o poder público.

A reflexão crítica, permitida pelo processo de investigação, poderá aprofundar o olhar sobre o que está sendo produzido nos territórios ditos vulneráveis neste contexto da pandemia. Que novas produções, novos arranjos, novas intervenções estão sendo construídas? Que papel os movimentos e organizações locais estão tendo nesse momento? Que interlocutores ganham ou perdem credibilidade? O que produz diferentes arranjos de enfrentamento da pandemia construídos na comunidade?

Espaços com vulnerabilidades não são espaços amorfos, que espelham sempre do mesmo jeito os indicadores que os identificam. São territórios plurais, com contradições e disputas dentro de cada um, com diferentes produções de coletivos, de organização, com histórias de intervenções que aumentam ou diminuem os efeitos perversos das desigualdades, com diferentes arranjos das violências e do enfrentamento dessas. Como assumido no desenho da pesquisa, território como espaço de produção de vida. Que vidas estão se produzindo nesses territórios neste momento de vivência da pandemia?
Para caminhar por essas questões, é preciso articular os vários momentos e arranjos da pesquisa, permitir a condução a partir do campo, criar espaços de análise que sejam atravessados por múltiplos olhares dos pesquisadores e das pessoas que participarão em cada campo. É central a composição do grupo de pesquisadores que agregam pessoas dos territórios estudados, estudantes, professores e técnicos ligados à universidade, possibilitando diferentes análises e processamentos do que for se desvelando ao longo da investigação. $\mathrm{O}$ pesquisador e o campo vão se produzindo nessa relação e são atravessados pelos muitos arranjos metodológicos ${ }^{21}$. Mais do que descrever a vivência e os impactos da pandemia nas populações estudadas, o principal objetivo e desafio central é visibilizar o processo e reconhecer criticamente as questões que vão se apresentando no decorrer da pesquisa.

Um desafio importante no processo de análise é a articulação entre a produção dos vários territórios. Coletivos diferentes em territórios singulares, que têm entre si várias características em comum e, também, muita diversidade. $\mathrm{O}$ investimento na produção em muitos territórios, em diferentes municípios com esse coletivo de pesquisadores é um desafio e uma prioridade no processo de desenvolvimento da pesquisa. Cada território produzirá sua investigação e análises a partir de construções teórico-metodológicas comuns em permanente compartilhamento. Alguns instrumentos da investigação permitem generalizações, outros aprofundam o singular, outros visibilizam as disputas, as relações, as potências e fragilidades de cada território, além do que é comum e diferente no conjunto desses.

\section{Resultados parciais da análise sobre os caminhos da pesquisa}

O desenvolvimento da pesquisa tem trazido elementos de análise a partir da perspectiva metodológica assumida que permitem 
visibilizar aspectos da vivência da pandemia nas populações estudadas a partir de múltiplos olhares, incluindo a perspectiva dos pesquisadores sociais que pertencem aos territórios.

Um primeiro aspecto é a reflexão sobre a existência de múltiplos territórios que até então eram percebidos como homogêneos pelos próprios pesquisadores sociais:

Conforme as perguntas eram respondidas pelo questionário me causou muita indignação e surpresa, porque naquela região do bairro onde eu estava, que é uma parte no começo da favela, não tem água e eu, como moradora do bairro há quase 17 anos, não sabia sobre essa questão. Me fez refletir bastante do quanto eu estou fechada para perceber algumas questões, mesmo que eu não perceba, eu não via o que acontecia no meu bairro antes da pesquisa. (Diário de campo, Pesquisador 2).

Esse deslocamento do pesquisador social sobre sua percepção do território onde vive e realiza a pesquisa amplia as dimensões que orientam o trabalho de campo, permitindo maior visibilidade para a multiplicidade de vivências da pandemia.

Também os pesquisadores ligados à universidade, a partir dos dispositivos metodológicos da pesquisa participativa, ampliam sua capacidade de análise sob a perspectiva da desterritorialização provocada pela entrada no campo acompanhado pelas lideranças locais:

Na entrada da comunidade Mário Cardim, esperando a liderança comunitária que iria nos guiar até as duas pessoas a serem entrevistadas, fiquei pensando em nossos últimos encontros sobre o campo e sobre como é importante e potente desnaturalizar o olhar: era uma 'nova Vila Mariana', tão próxima de meu cotidiano, mas, ao mesmo tempo, um 'enclave', uma 'ilha' formada pela comunidade e seus/suas habitantes em meio às casas grandes e requintadas ao redor. (Diário de campo, Pesquisadora 3).

Essa desterritorialização tem sido fundamental para a realização de um dos pressupostos centrais da metodologia, que é o de não fazer uma investigação sobre as pessoas, mas com as pessoas; e que se estrutura no intercruzamento dos saberes de diferentes disciplinas que se permitem afetar pelo campo, pelo deslocamento de olhares e pela produção que esta vivência da pesquisa vem permitindo.

\section{Considerações finais}

Construir um desenho de pesquisa que permita qualificar o olhar sobre a vivência da pandemia, partindo da perspectiva de seus efeitos nas populações vulneráveis, amplifica a visão sobre a desigualdade social nas suas múltiplas dimensões e pressupõe o fortalecimento de uma produção interdisciplinar. Os necessários múltiplos olhares ante a complexidade do objetivo colocado, ao mesmo tempo que levam à produção de um olhar comum, aprofundam as singularidades de cada espaço de pesquisa.

Esse desafio ganha outra complexidade com a entrada de experiências, saberes e histórias diversos, que passam a compor esse coletivo. $\mathrm{O}$ arranjo territorial e de composição do coletivo pesquisador ensejou a construção de um desenho gestor da pesquisa que dialogasse com essas características. O desafio central é a busca pela construção de estratégias de constituição de espaços de articulação, reflexão, formação e implementação de estratégias comuns, envolvendo o conjunto de pesquisadores dos seis campi, a formação de grupos de trabalho temáticos, envolvendo pesquisadores de todos os campi da universidade, a partir de uma necessidade específica.

Ampliar a interação entre os saberes, reconhecer a complexidade dos processos de produção social, superar a perspectiva de cada olhar especializado, sem perder a potência e importância desses na construção do conhecimento, na reflexão crítica e intervenção nas várias dimensões e problemas da vida dos brasileiros, têm orientado o cotidiano da pesquisa.

A opção metodológica orientada pelas necessidades manifestas da sociedade coloca 
centralidade nos territórios escolhidos, com suas singularidades, diversidades, conflitos e potências. Estar nesses territórios, construindo nossa entrada com as lideranças de cada comunidade, pactuando o processo da pesquisa, nos constituindo em ato como um coletivo de pesquisadores de um mesmo projeto, tem ampliado a capacidade de reconhecer dimensões da vivência da pandemia naquela comunidade. Compor um grupo de pesquisa conformado por investigadores que moram nas favelas, nos assentamentos, na rua, no conjunto habitacional, em loteamentos irregulares, integrantes de movimentos sociais, alunos de graduação e do ensino médio, docentes e técnicos da universidade, unidos pelo esforço de constituição desse coletivo pesquisador, tem sido uma experiência que permite evidenciar a potência da metodologia participativa no desenvolvimento de pesquisas que se colocam na perspectiva definida pelos objetivos desta investigação.

Tem sido central na pesquisa a perspectiva de aprofundar uma reflexão crítica e dar visibilidade aos modos de produzir vida em territórios marcados pela desigualdade. A interlocução e a participação efetiva em espaços de organização coletiva e redes de solidariedade em cada território, que inventam cotidianamente jeitos de enfrentar os desafios que ali se apresentam, têm aprofundado a importância de a universidade estar presente e construir conhecimento comprometido com a produção da vida. Poder caminhar junto nesse complexo processo atravessado pela pandemia é o desafio e a riqueza deste estudo.

\section{Colaboradores}

Furtado LAC (0000-0001-7897-9739)*, Fegadolli C (0000-0002-2991-0206)* e Chioro A (0000-0001-7184-2342)*, contribuíram para concepção, planejamento, análise e interpretação dos dados; elaboração do rascunho e revisão crítica do conteúdo; e aprovação da versão final do manuscrito. Nakano AK (0000-0002-1929-5270)*, Silva CG (00000002-1169-7224)*, Paula L (0000-0002-07551468)*, Souza LR (0000-0003-4581-094X)* e Nasser MA (0000-0001-8409-7265)* contribuíram para concepção, planejamento, análise e interpretação dos dados; e elaboração do rascunho e revisão crítica do conteúdo. 


\section{Referências}

1. Neri MC. A escalada da desigualdade - qual foi o impacto da crise sobre a distribuição de renda e a pobreza? [internet] Rio de Janeiro: FGV Social; 2019. [acesso em 2020 jun 29]. Disponível em: https://cps. fgv.br/desigualdade.

2. Martins M. A pandemia expõe de forma escancarada a desigualdade social. Videoconferência [internet] 2020. [acesso em 2020 jun 29]. Disponível em: https:// www.sct.ce.gov.br/2020/04/25/a-pandemia-expoe-de-forma-escancarada-a-desigualdade-social/.

3. Santos JAF. Covid-19, causas fundamentais, classe social e território. Trab. educ. saúde. [internet]. 2020 [acesso em 2020 jun 28]; 18(3):e00280112. Disponível em: https://www.scielo.br/pdf/tes/v18n3/01026909-tes-18-3-e00280112.pdf.

4. Brasil. Ministério da Saúde. Painel Coronavírus. [internet] 2020. [acesso em 2020 set 10]. Disponível em: https://covid.saude.gov.br/.

5. Medida SP. Um laboratório de visualização urbana [internet]. 2020. [acesso em 2020 jun 30]. Disponível em: https://medidasp.com/.

6. Mbembe A. Pandemia democratizou poder de matar. [entrevista concedida a Diogo Bercito]. Folha de São Paulo [internet] 2020 mar 30 [acesso em 2020 jun 28]. Disponível em: https://wwwl.folha.uol.com.br/mundo/2020/03/pandemia-democratizou-poder-de-matar-diz-autor-da-teoria-da-necropolitica.shtml.

7. Kincheloe J, Berruy K. Pesquisa em educação: conceituando a bricolagem. Porto Alegre: Artmed; 2007.

8. Paulon SM. A análise de implicação como ferramenta na pesquisa-intervenção. Psicol. Soc. (online). 2005 [acesso em 2020 nov 24]; 17(3):18-25. Disponível em: https://www.scielo.br/scielo.php?pid=S0102$-71822005000300003 \&$ script=sci_abstract\&tlng=pt.

9. Universidade Federal de São Paulo. São Paulo: UNIFESP; [2019]. [acesso em 2020 jun 26]. Disponível em: https://www.unifesp.br/.
10. Bock A. A psicologia no Brasil e suas relações com o Marxismo. In: Vilela AMJ, Ferreira AAL, Portugal FT, organizadores. História da Psicologia: rumo e percursos. Rio de Janeiro: Nau; 2006.

11. Yin RR. Estudo de caso: Planejamento e métodos. Porto Alegre: Bookman; 2014.

12. Gil AC. Como elaborar projetos de pesquisa. 4. ed. São Paulo: Atlas; 2002.

13. Freire P. Paulo Freire \& educadores de rua: uma abordagem crítica. Colômbia: UNICEF; SAS; FUNABEM; 1987.

14. Oliveira MD, Oliveira RD. Pesquisa Social e Ação Educativa: Conhecendo a realidade para poder transformá-la. In: Brandão CR, organizador. Pesquisa participante. São Paulo: Brasiliense; 1984. p. 17-33.

15. Paiva V, Pupo L, Seffner F. Educação em saúde e emancipação: explorando a possibilidade de prevenção no quadro dos Direitos Humanos. In: Paiva V, Pupo L, Seffner F, organizadores. Vulnerabilidade e Direitos Humanos - Prevenção e promoção da saúde. Curitiba: Juruá; 2012. p. 9-26. (Livro III: Pluralidade de vozes e inovação de práticas).

16. Moebus NM, Merhy EE, Silva E. O usuário-cidadão como guia. Como pode a onda elevar-se acima da montanha? In: Merhy EE, Baduy RS, Seixas CT et al., organizadores. Avaliação compartilhada do cuidado em saúde: surpreendendo o instituído nas redes. Rio de Janeiro: Hexis; 2016. p. 43-53. (Livro 1).

17. Minayo MCS. O desafio do conhecimento. 11. ed. São Paulo: Hucitec; 2008.

18. Martins HHTS. Metodologia qualitativa de pesquisa. Educação e Pesquisa. 2005; 30(2):289-300; 2004.

19. Reis AAC, Soter APM, Furtado LAC, et al. Tudo a temer: financiamento, relação público e privado e o futuro do SUS. Saúde debate [internet]. 2016 [acesso em 2020 jun 28]; 40(esp):186-200. Disponível em: 
https://www.scielo.br/pdf/sdeb/v40nspe/0103-1104sdeb-40-spe-0122.pdf.

20. Feuerwerker LCM, Merhy EE, Silva E. Como temos armado e efetivado nossos estudo que fundamentalmente investigam políticas e práticas sociais em saúde? In: Feuerwerker LCM, Bertussi D, Merhy EE, organizadores. Avaliação Compartilhada do cuidado em saúde: surpreendendo o instituído nas redes. Rio de Janeiro: Hexis; 2016. p. 10-24. (Livro 2).
21. Bertussi DC, Baduy RS, Feuerwerker LCM, et al. Viagem Cartográfica: pelos trilhos e desvios. In: Feuerwerker LCM, Bertussi DC, Merhy EE, organizadores. Avaliação Compartilhada do cuidado em saúde: surpreendendo o instituído nas redes. Rio de Janeiro: Hexis; 2016. p. 48-61. (Livro 2).

Recebido em 30/06/2020

Aprovado em 02/11/2020

Conflito de interesses: inexistente

Suporte financeiro: Fundação Tide Setubal 